Supplement of Hydrol. Earth Syst. Sci., 20, 2001-2018, 2016

http://www.hydrol-earth-syst-sci.net/20/2001/2016/

doi:10.5194/hess-20-2001-2016-supplement

(C) Author(s) 2016. CC Attribution 3.0 License.

(c) (1)

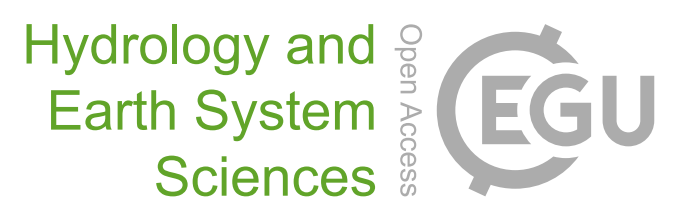

Supplement of

\title{
Combined measurement and modeling of the hydrological impact of hy- draulic redistribution using CLM4.5 at eight AmeriFlux sites
}

\section{Congsheng Fu et al.}

Correspondence to: Guiling Wang (gwang@engr.uconn.edu)

The copyright of individual parts of the supplement might differ from the CC-BY 3.0 licence. 
(a) Oak Pine Forest (US-SCf)

言 0.18 - Rhythmic ${ }_{\text {noise }}^{0.18}$ CS-229 Probes

है $0.14 \quad 200 \mathrm{~cm}$.

प. $0.12 \quad 100 \mathrm{~cm}$

है $0.150 \mathrm{~cm}$.

I $25 \mathrm{~cm}$

$0.085 \mathrm{~cm} 10 \mathrm{~cm}$

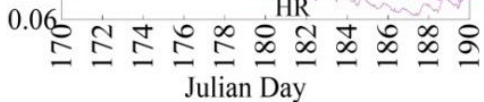

(c) Desert Chaparral (US-SCc)

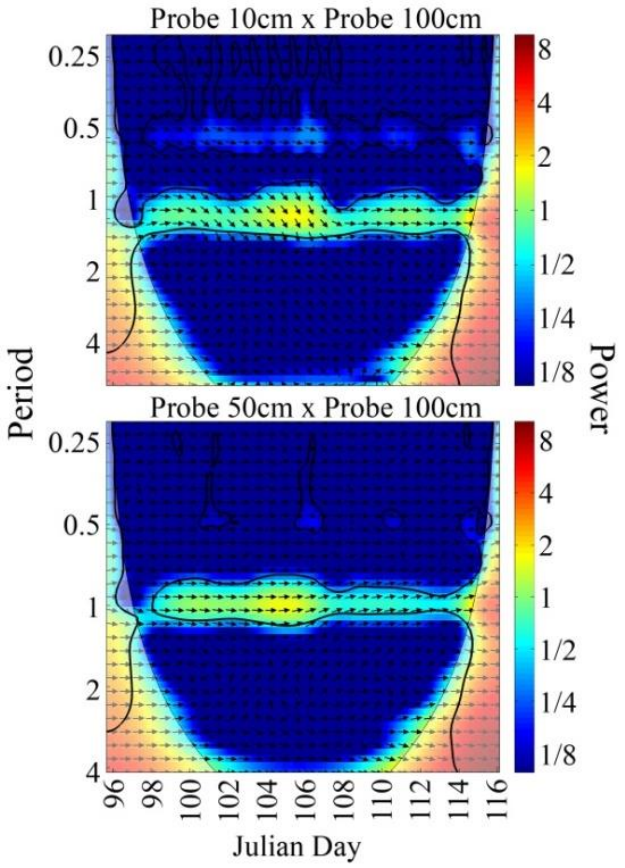

(d) Field data

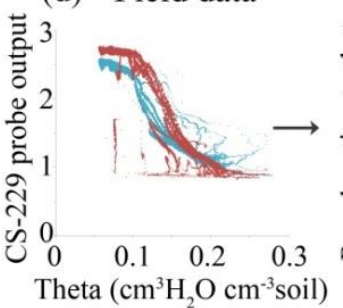

Theta $\left(\mathrm{cm}^{3} \mathrm{H}_{2} \mathrm{O} \mathrm{cm}{ }^{-3} \mathrm{soil}\right)$ from CS-616 probes integrating $0-30 \mathrm{~cm}$ moisture (b) Oak Pine Forest (US-SCf)

Probe $5 \mathrm{~cm}$ x Probe $200 \mathrm{~cm}$

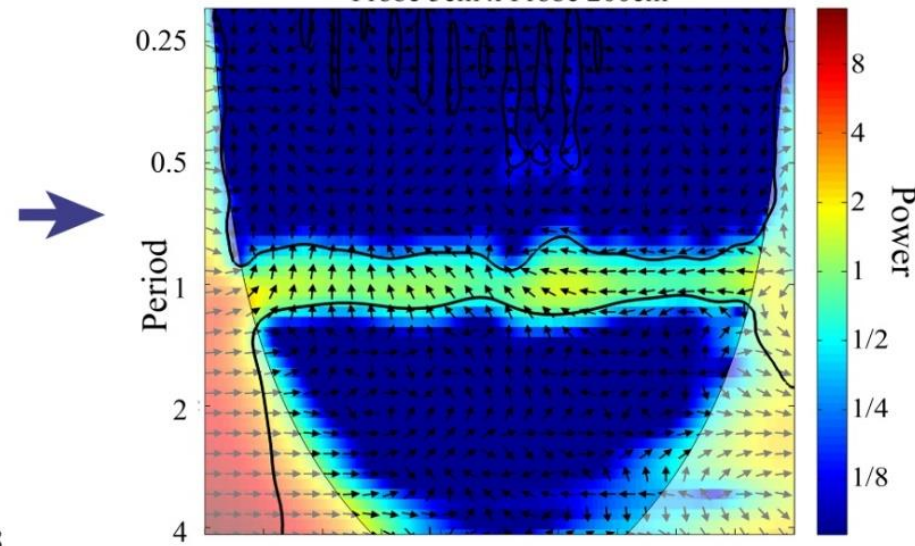

Probe $10 \mathrm{~cm} \times$ Probe $200 \mathrm{~cm}$

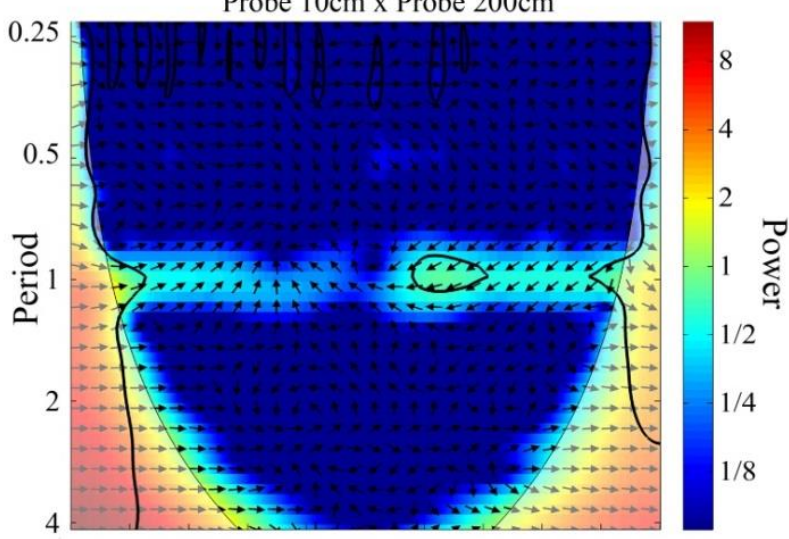

Probe $100 \mathrm{~cm} \times$ Probe $200 \mathrm{~cm}$

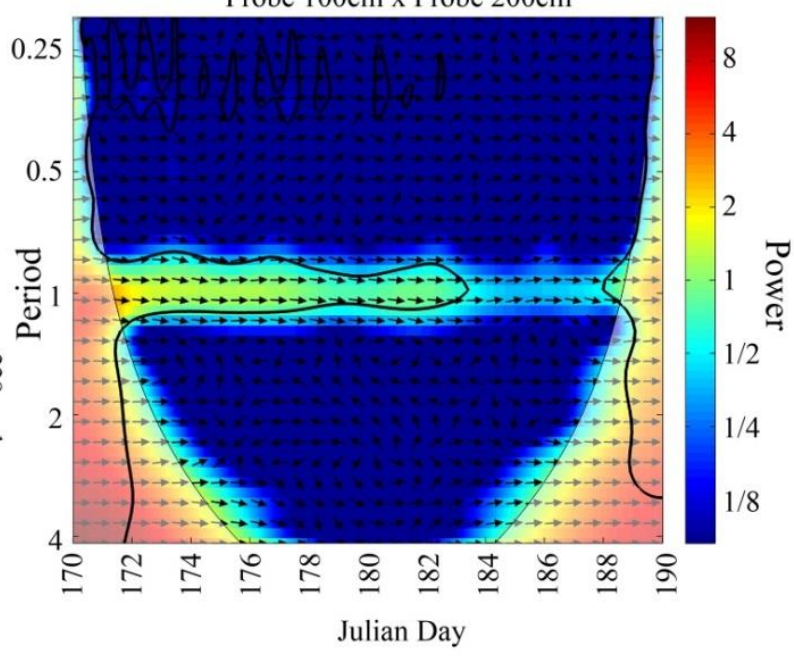

Fig. S1. 


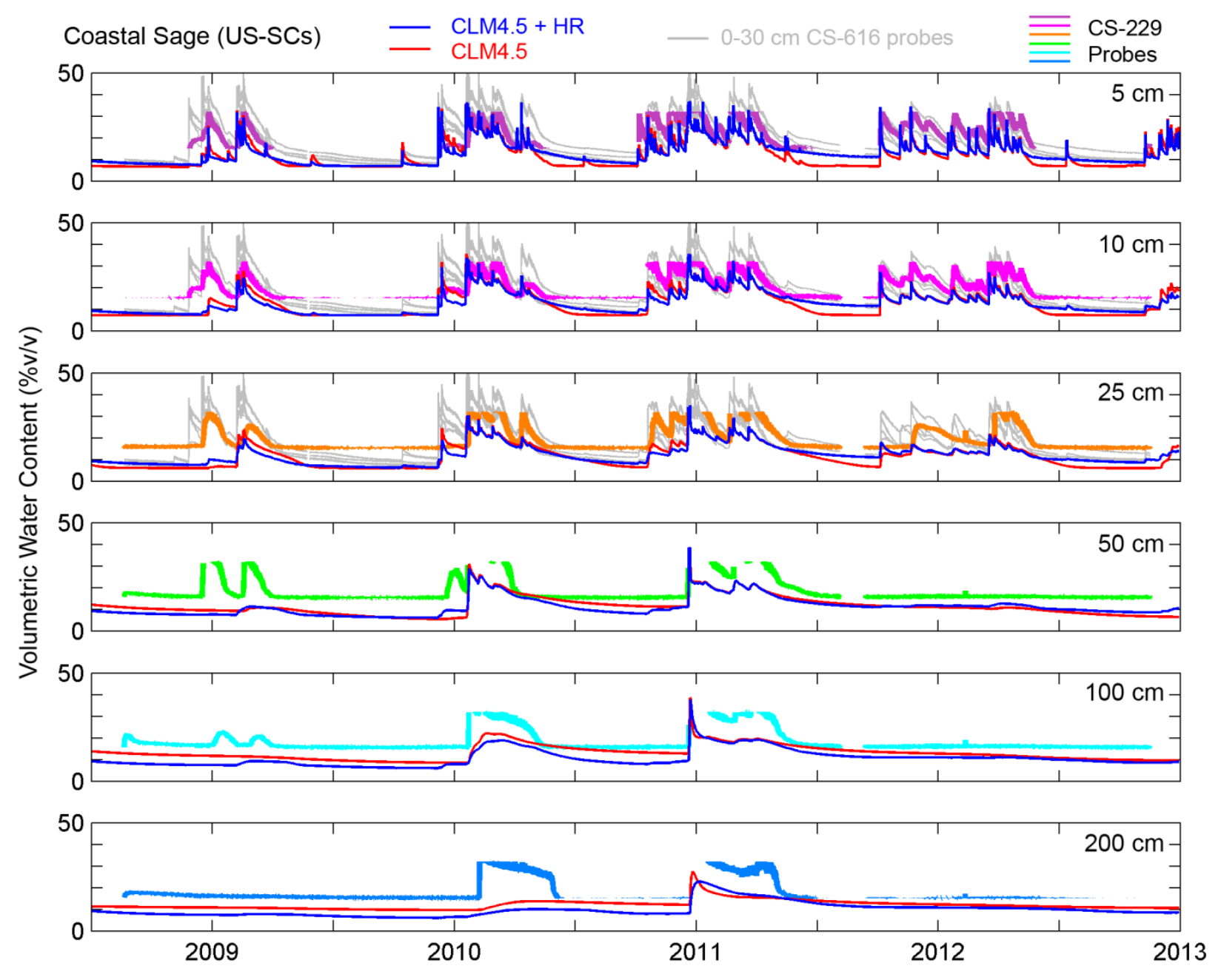

Fig. S2. 

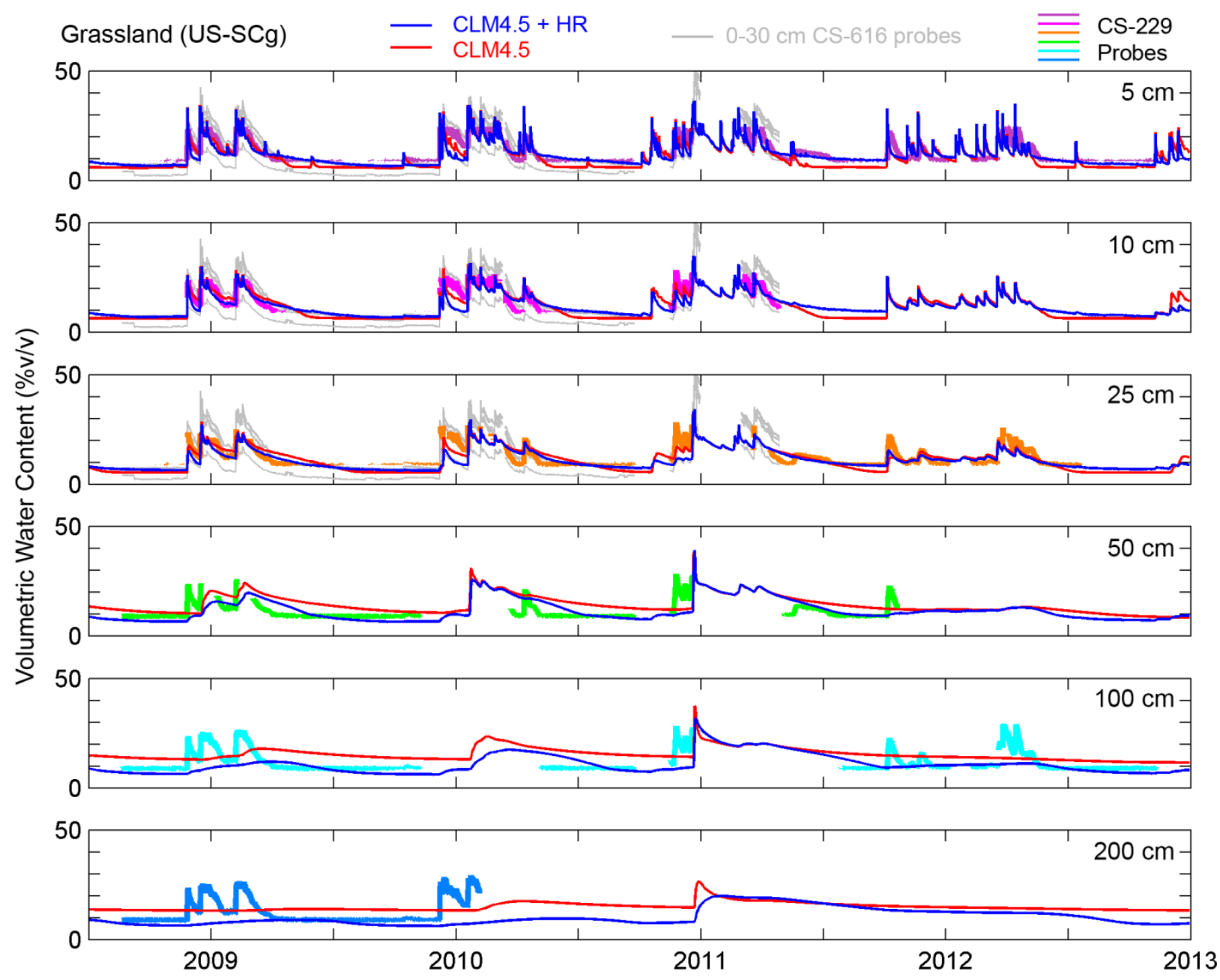

Fig. S3. 


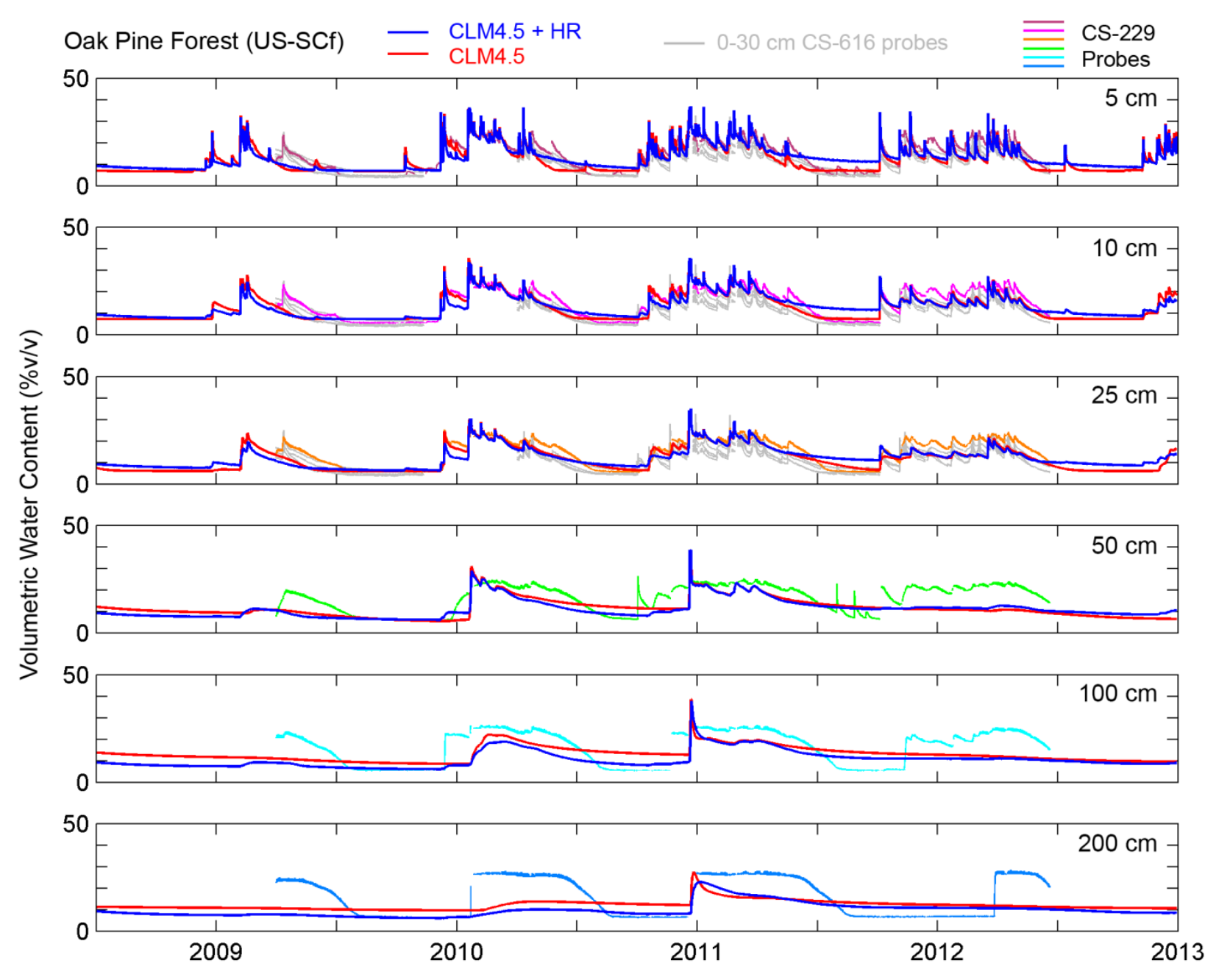

Fig. S4. 

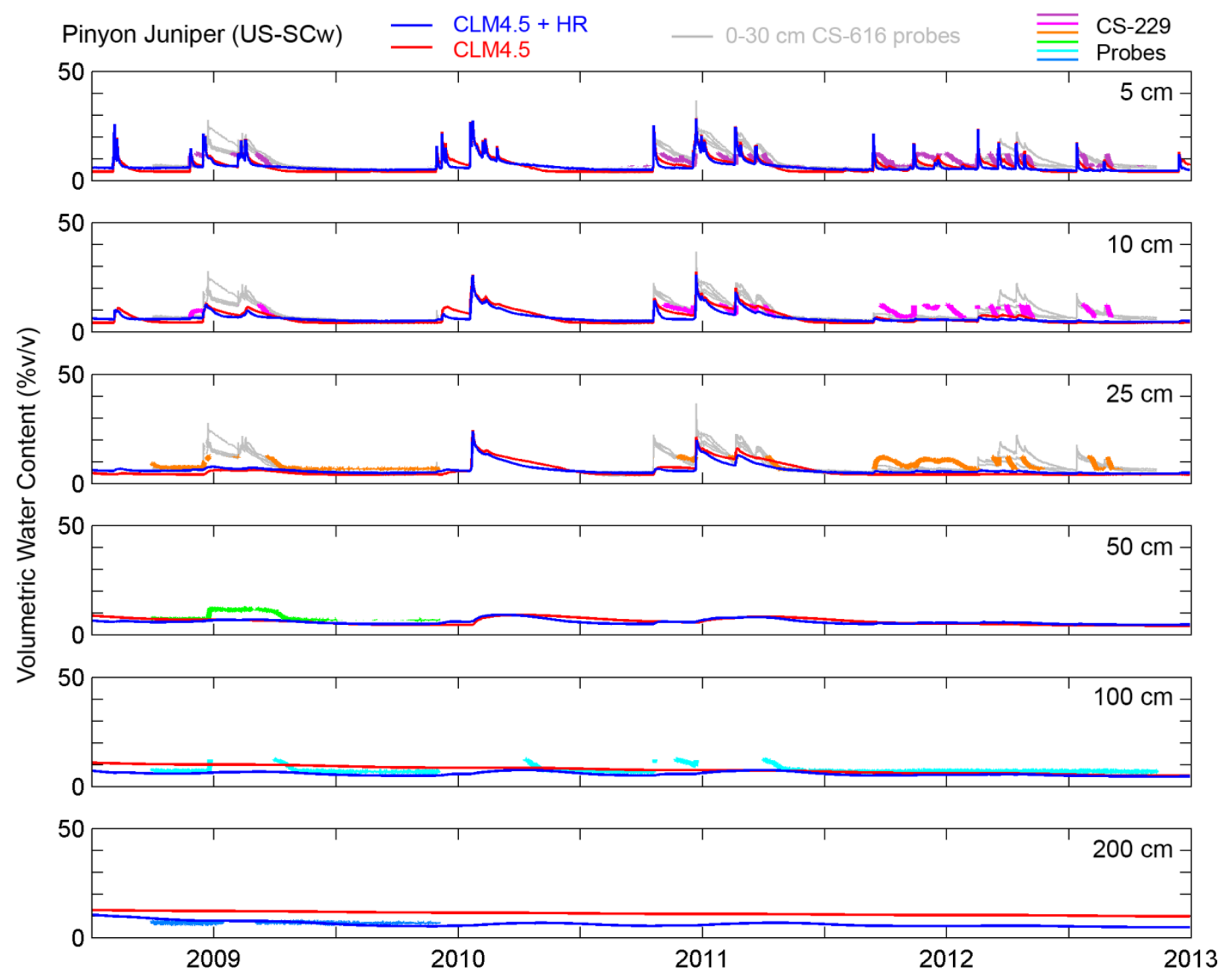

Fig. S5. 

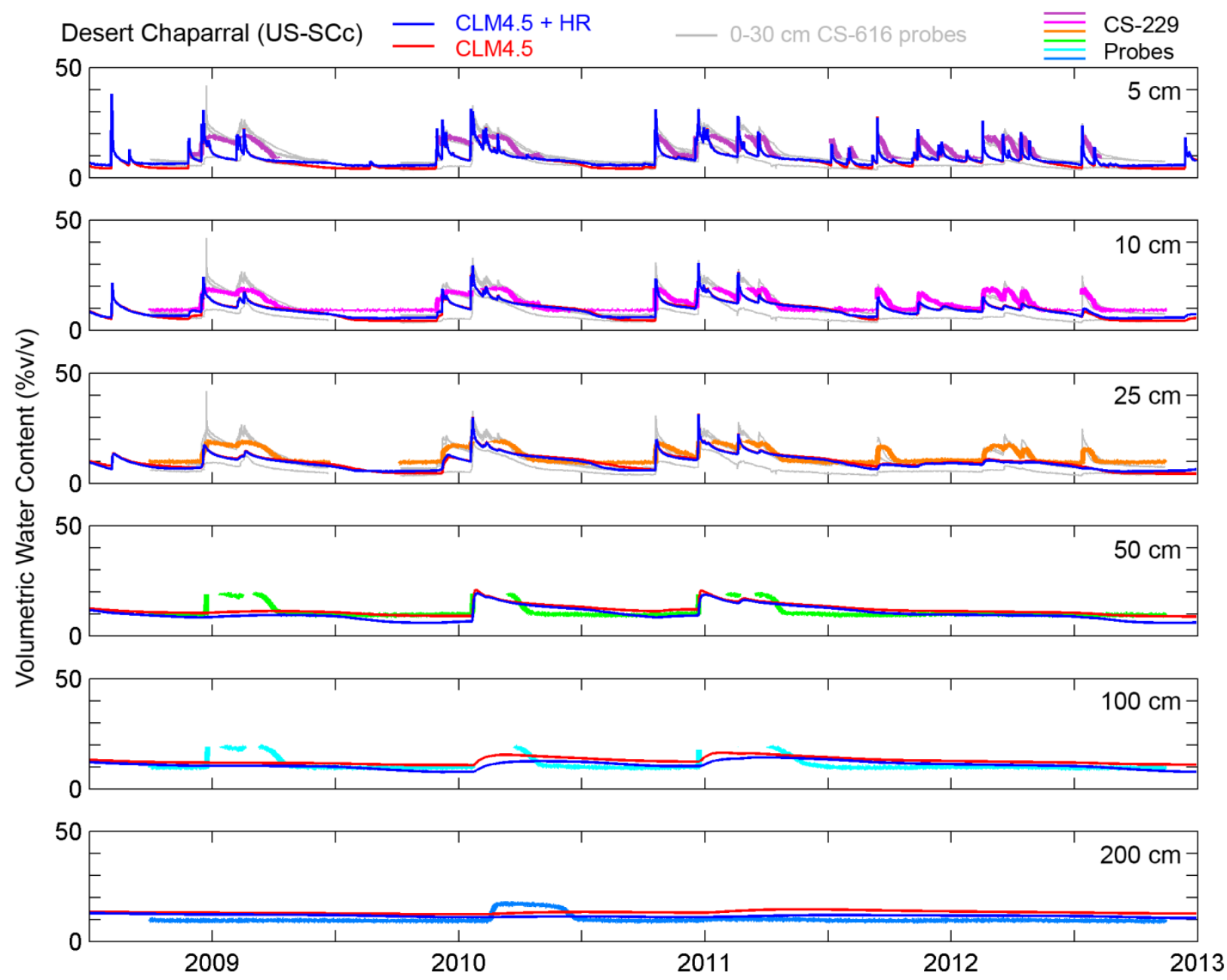

Fig. S6. 
Mean of observation

Mean of simulation with HR
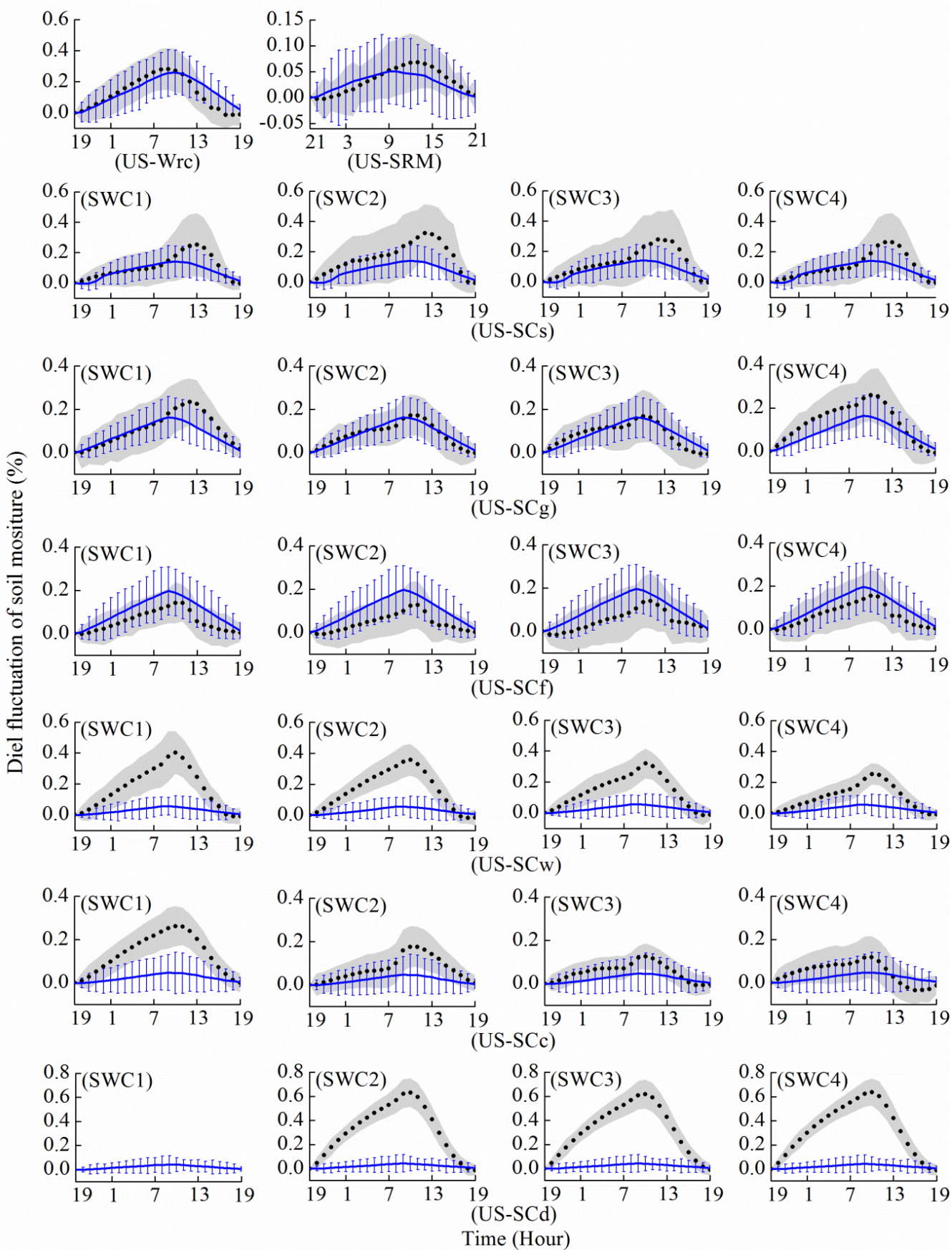

Time (Hour)

Fig. S7. 
- Simulation without HR $\boldsymbol{\nabla}$ Simulation with HR
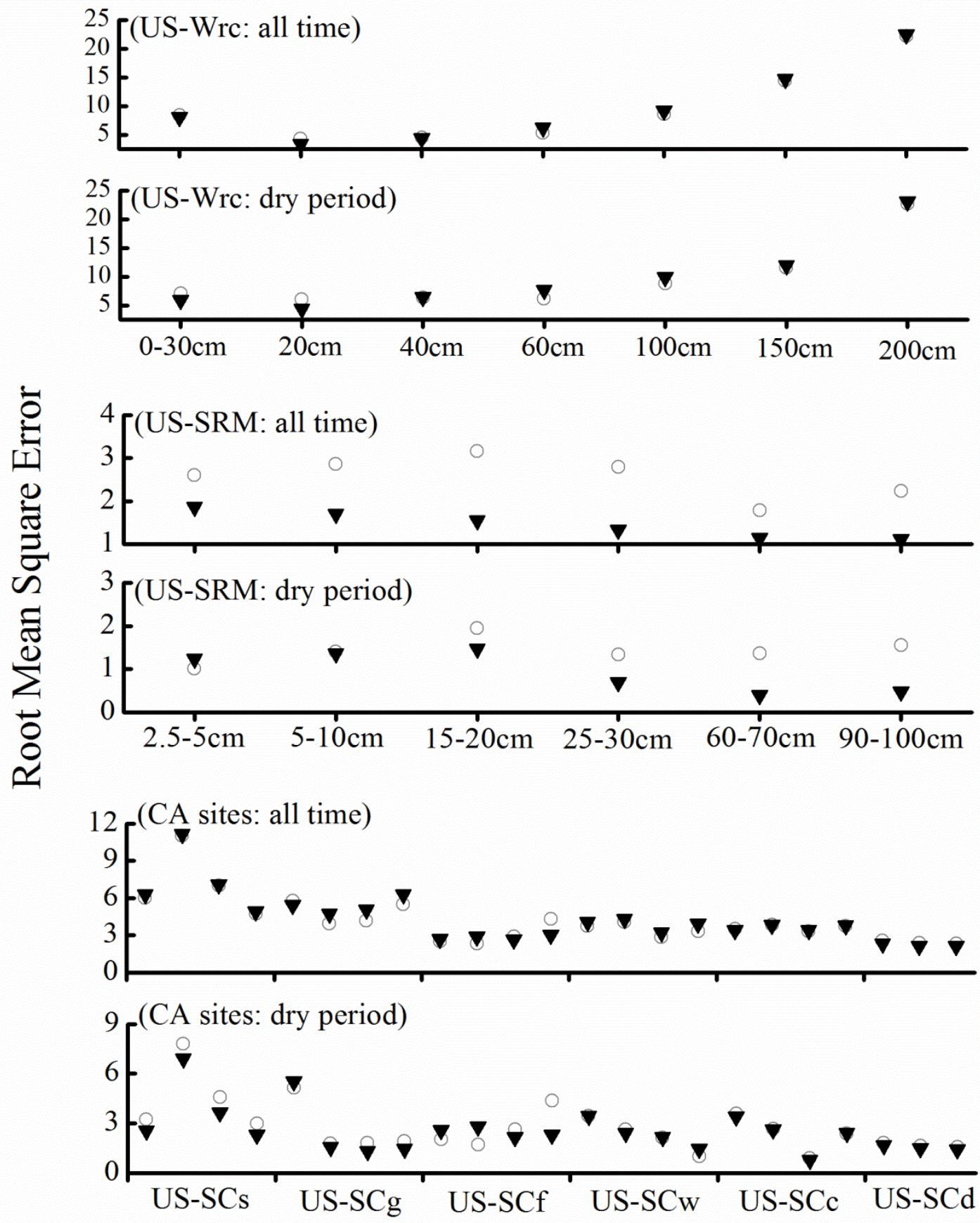

Fig. S8. 


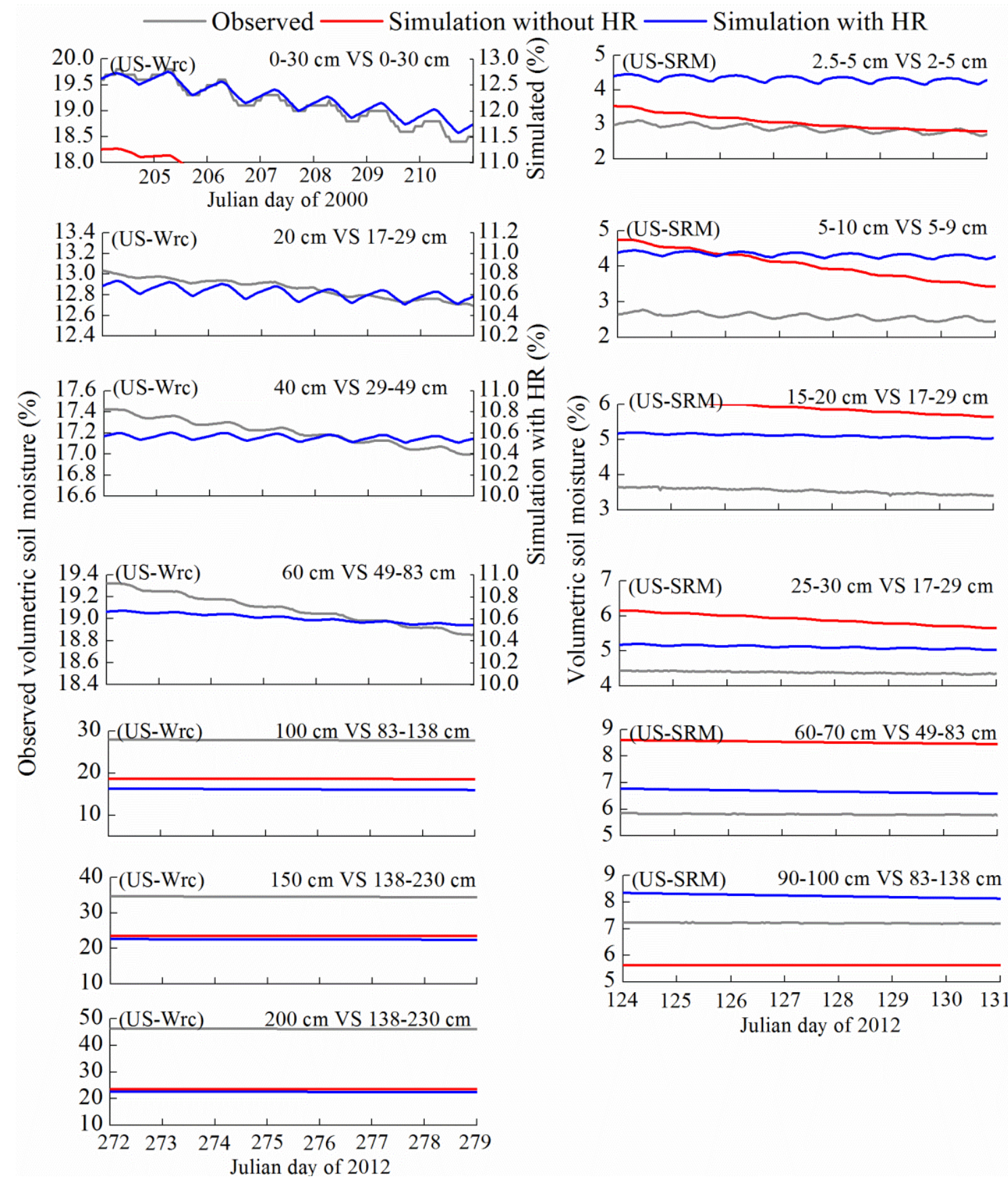

Fig. S9. 


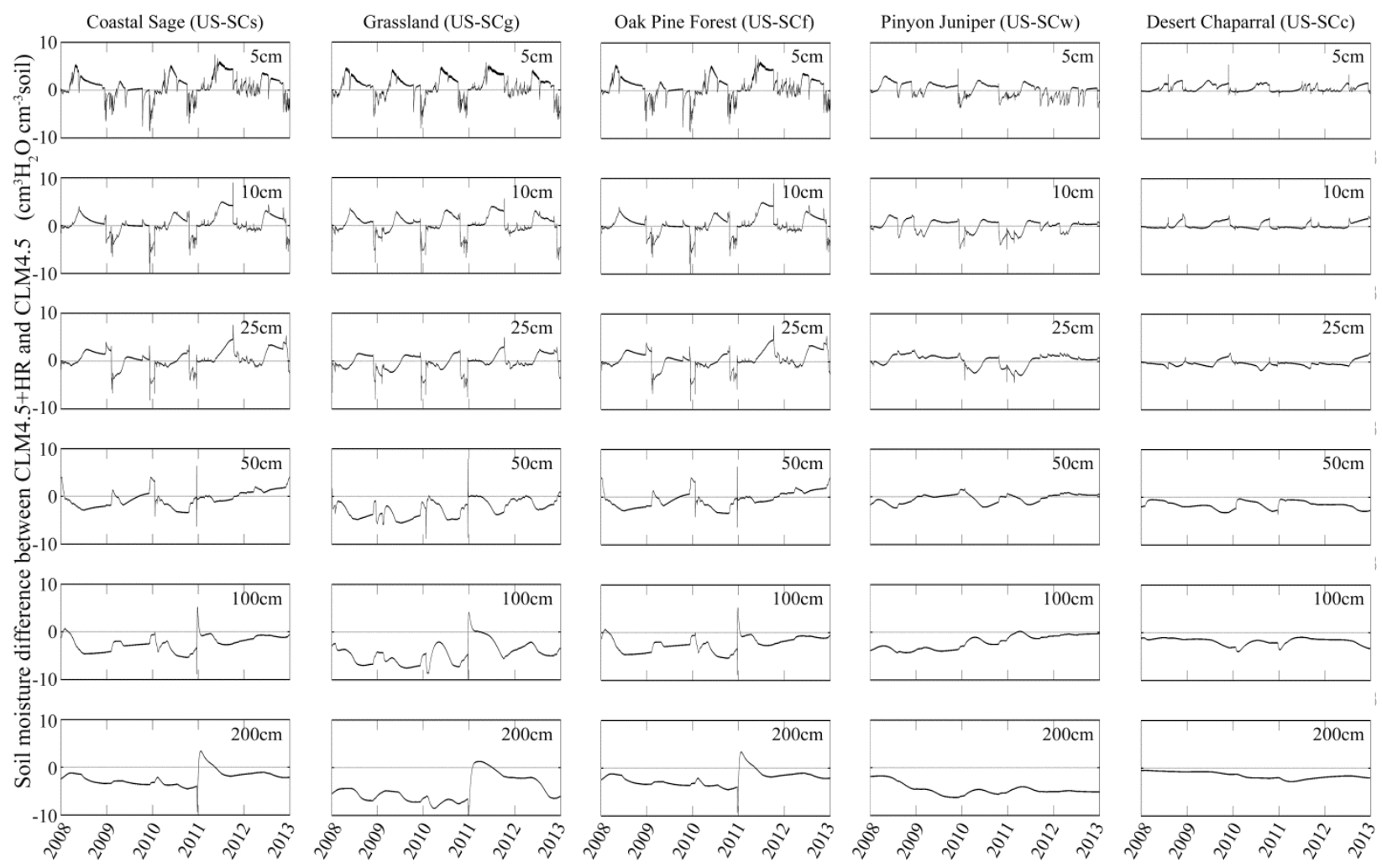

Fig. S10. 


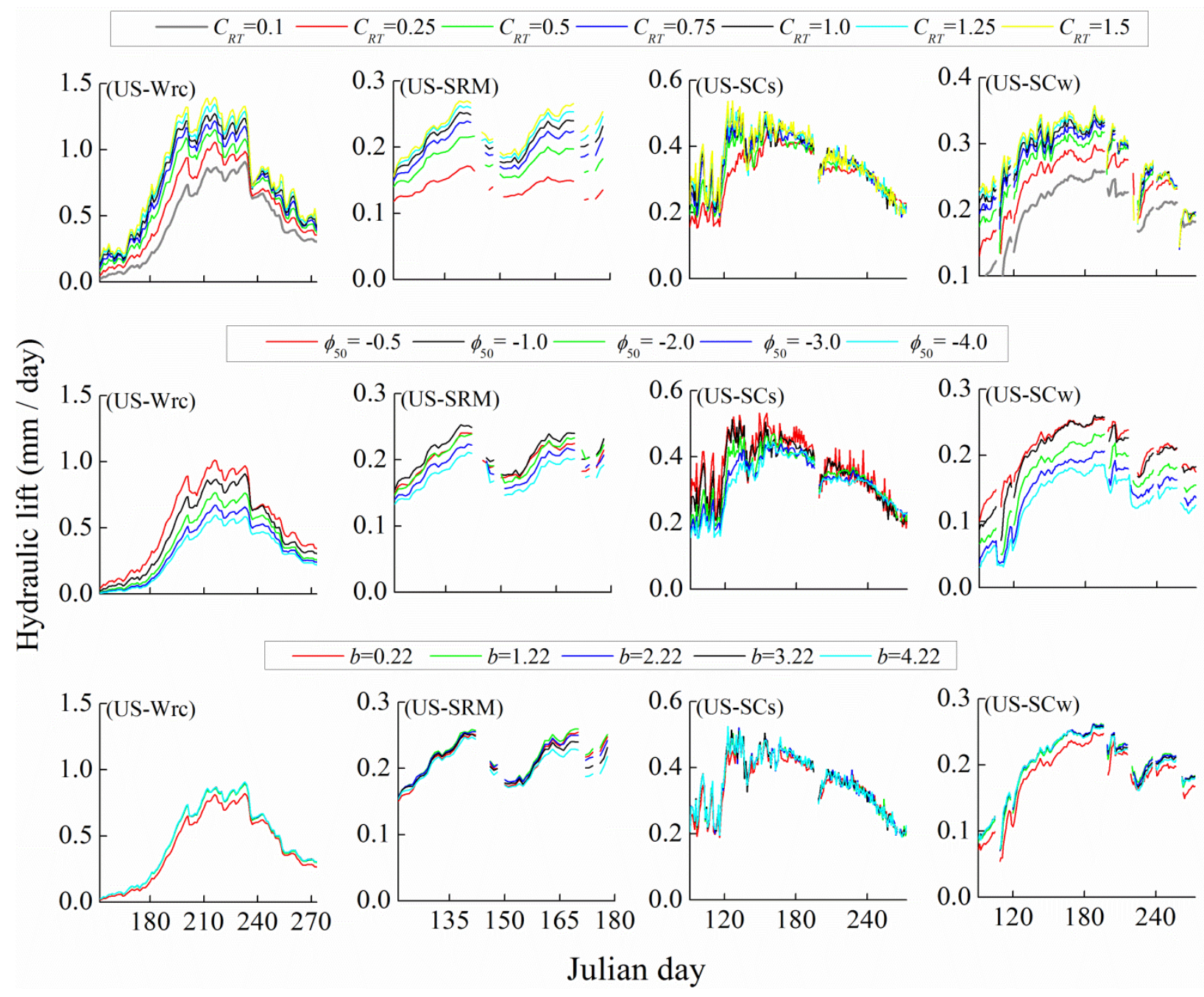

Fig. S11. 


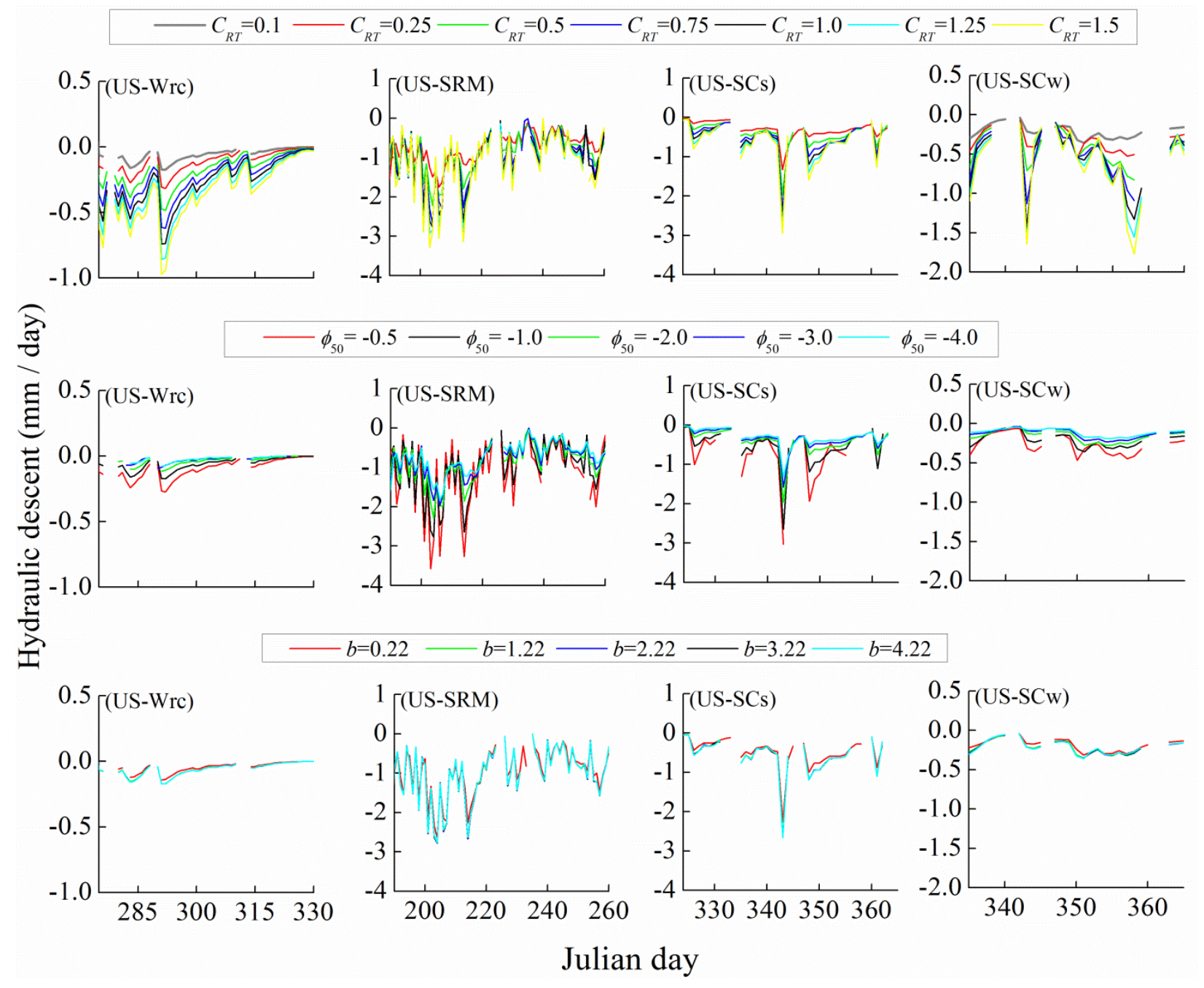

Fig. S12. 


\section{Supplementary Text}

\section{Notes S1}

Surface properties were drawn by interpolation from corresponding gridded datasets in the NCAR database (Oleson et al., 2013) in the absence of site-specific data. Specifically, prescribed soil colors are from Lawrence \& Chase (2007) with a base spatial resolution of $0.5^{\circ}$. A prescribed mineral soil texture dataset, with a base spatial resolution of $0.083^{\circ}$, is from the International Geosphere-Biosphere Programme (IGBP) (Bonan et al., 2002). Leaf and stem area indices and canopy heights are prescribed for each PFT if the biogeochemistry model is inactive (as it is in this study). Prescribed percent PFTs $\left(0.05^{\circ}\right)$ are derived from Moderate Resolution Imaging Spectroradiometer (MODIS) satellite data (Lawrence \& Chase, 2007). Prescribed leaf area index for each PFT $\left(0.5^{\circ}\right)$ is derived from the MODIS satellite data of Myneni et al. (2002). Prescribed stem area index for each PFT is derived from the corresponding leaf area index using the methods of Zeng et al. (2002). And, prescribed canopy top and bottom heights are from Bonan (1996). Rooting distribution at all sites is derived from Jackson et al. (1996).

Bonan GB (1996) A land surface model (LSM version 1.0) for ecological, hydrological, and atmospheric studies: Technical description and user's guide. NCAR Technical Note NCAR/TN417+STR, National Center for Atmospheric Research, Boulder, CO, 150 pp.

Bonan GB, Levis S, Kergoat L, Oleson KW (2002) Landscapes as patches of plant functional types: An integrating concept for climate and ecosystem models. Global Biogeochemical Cycles, 16 (2), 5.15.23 .

Lawrence PJ, Chase TN (2007) Representing a MODIS consistent land surface in the Community Land Model (CLM 3.0). Journal of Geophysical Research, 112: G01023. DOI: 10.1029/2006JG000168.

Myneni RB, Hoffman S, Knyazikhin Y et al. (2002) Global products of vegetation leaf area and fraction absorbed PAR from year one of MODIS data. Remote Sensing of Environment, 83, 214-231.

Zeng X, Shaikh M, Dai Y, Dickinson RE, Myneni R (2002) Coupling of the Common Land Model to the NCAR Community Climate Model. Journal of Climate, 15, 1832-1854. 


\section{$\underline{\text { Notes S2 }}$}

Soil moisture data for the six Southern California gradient sites (US-SCs, g, f, w, c, d) were obtained from the Goulden lab (http://www.ess.uci.edu/ california/). Each site had four CS-616 water content reflectometers (each sensing 0-30 cm depth). All sites except the driest (US-SCd, Sonoran Desert) also had five CS-229 thermal dissipation probes installed a single profile at 5, 10, 25, 100, and $200 \mathrm{~cm}$ depths. CS-229 probes were not calibrated in the lab, so a rough field calibration was developed by comparing the 5, 10, and $25 \mathrm{~cm} \mathrm{CS}-229$ probe output with the CS-616 water content reflectometer data (measuring 0-30 cm soil water content, inclusive). Two approaches were used. In the first, output from the profile sensors was calibrated from field data by grouping the 5,10 , and $25 \mathrm{~cm}$ probe output, corrected to $20{ }^{\circ} \mathrm{C}$, and graphing it against the natural log of the soil matric potential as specified in the calibration section of the CS-229 manual. That matric potential was calculated from the temperaturecorrected soil moisture data from $0-30 \mathrm{~cm}$ CS-616 probes combined with expected water retention characteristics for the site soil types (Clapp and Hornberger ,1978). The ranges of these parameters for different soil types are quite large and strongly affect calculation of matric potential. So, the known insensitivity of the CS-229 probes at water potentials below -2.5 MPa was also used; probe output clearly flatlined as soils dried. The best fit single calibration was applied to all five sensors at each site.

A second more conservative field calibration was then developed. Rather than translating the CS-616 output to water potential using the generalized Clapp and Hornberger (1978) parameters, we instead simply compared the CS-229 and CS-616 outputs directly, and found ranges of soil moisture within which there were clear dynamics in CS-229 output. A sample of the relationship is shown in Fig. S1d, from the Desert Chapparal US-SCc site. Using only the data from CS-229 output within the sensors' dynamic range, CS-229 output was translated into a rough estimate of soil water content, at the 5, 10, 25, 50, 100, and $200 \mathrm{~cm}$ depths. Data are presented as colored lines, one per panel, for each site and depth at each site (Figs S2-6). Water content predicted at the various depths by CLM4.5+HR and CLM4.5 is also included as blue and red lines, respectively. CS-229 data were already more spotty than CS-616 data from each site, and by using output only in the CS-229 dynamic range, information from these probes is spotty and confined to mid-ranges of soil moisture content. Still, the data are 
informative, in that they show that throughout the soil column, there are clear time periods in which deep soil moisture is quite dynamic.

During windows of time when sensors were operating and soil moisture was at its mid-range, the CS-229 sensors had the potential to provide enough information to use in wavelet analysis to detect the signature of upward hydraulic redistribution. However, the analysis was complicated by several factors. After temperature correction following manufacturer directions, diel variation in CS-616 and CS-229 sensor output persisted throughout the time periods observed, likely for several reasons. The CS-616 temperature correction algorithm was developed from $10-40^{\circ} \mathrm{C}$, with constant temperature along the $30 \mathrm{~cm}$ long CS-616 rod; however, temperatures at the sites dipped below $10^{\circ} \mathrm{C}$, and the separate CS-229 probes at 5, 10, and $25 \mathrm{~cm}$ reported that temperatures were not constant in the soil column from 0 to $30 \mathrm{~cm}$. CS-616 temperature correction is therefore imperfect, but data are still useful with caveats. The CS-229 correction is presented in the manual from 10 to $30^{\circ} \mathrm{C}$, and the sensors themselves are described as having output linearly related to the ln of matric potential only down to -2.5 MPa. Temperatures at the sites dipped below $10^{\circ} \mathrm{C}$, above $30^{\circ} \mathrm{C}$, and soil water potential dropped significantly below -2.5 MPa for large portions of the dry season. Also, small diel oscillations in sensor output, of similar magnitude from all probes at some sites, no matter their depth, and varying as a function not of local temperature at the sensors themselves but instead air temperature and soil surface temperature, all were consistent with the possibility that the reference thermistor and sensor connection points in the measurement junction box aboveground were separated enough thermally for a gradient to develop on a diel rhythm. Again, temperature correction and sensor output are therefore imperfect, but still useful.

Data from both soil moisture sensor types at the Southern California sites were used conservatively. For the large changes in soil moisture content over seasons, the CS-616 output reflected influences of rainstorms and the mid-year dry season drydown of soil; model output is compared to these data in Fig. 1. In the literature, sensor output indicating nighttime increases in soil moisture followed by daytime decreases are used as a signature of HR, but we only recognized such oscillations from the $0-30 \mathrm{~cm}$ CS-616 or CS-229 probes as signatures of HR if they were clearly stronger than putative temperature-induced oscillations in surrounding portions of the signal trace (e.g. Fig. S1a, 
larger oscillations beginning around day 180 in the $5 \mathrm{~cm}$ trace.) We used the CS-229 probe output largely to corroborate CS-616 information, identifying time periods where HR is likely occurring at the sites. We made use of the putative temperature-induced oscillations (of one day period, labeled "rhythmic noise" in Fig. S1a) as a regular signal visible in all the sensor streams, and we used wavelet analysis (downloaded from http://www.glaciology.net/wavelet-coherence) within Matlab (Mathworks, Natick, MA) to detect periods of possible HR as a shift in the phase of the oscillation (Fig. S1b \& c). This approach allowed detection of upward HR to the 5 and $10 \mathrm{~cm}$ probes no matter the depth of source water.

Clear periodicity in signal is detected at all depths (hot colors across all days, at period 1 day). But the phase of periodicity for the 5 and $10 \mathrm{~cm}$ depth probes shifts in the middle of the time course, when HR occurs; this shift in phase is indicated by the directionality of the arrows superimposed on each panel in Fig. S1b. Arrows pointing to the right indicate signals are in phase. Arrows pointing to the left indicate signals are 180 degrees out of phase. This HR-linked phase shift occurred because HR drives an oscillation in sensor output of 1 day period but different timing from the putative temperature oscillation; HR increases sensor output in upper soil layers during the night. Fig. S1b \& c show example wavelet data from the Oak Pine Forest site (US-SCf) at James Reserve, where upward HR was previously analyzed by Kitajima et al. (2013), and the Desert Chaparral site (US-SCc), where HR has not been previously studied.

\section{$\underline{\text { Notes S3 }}$}




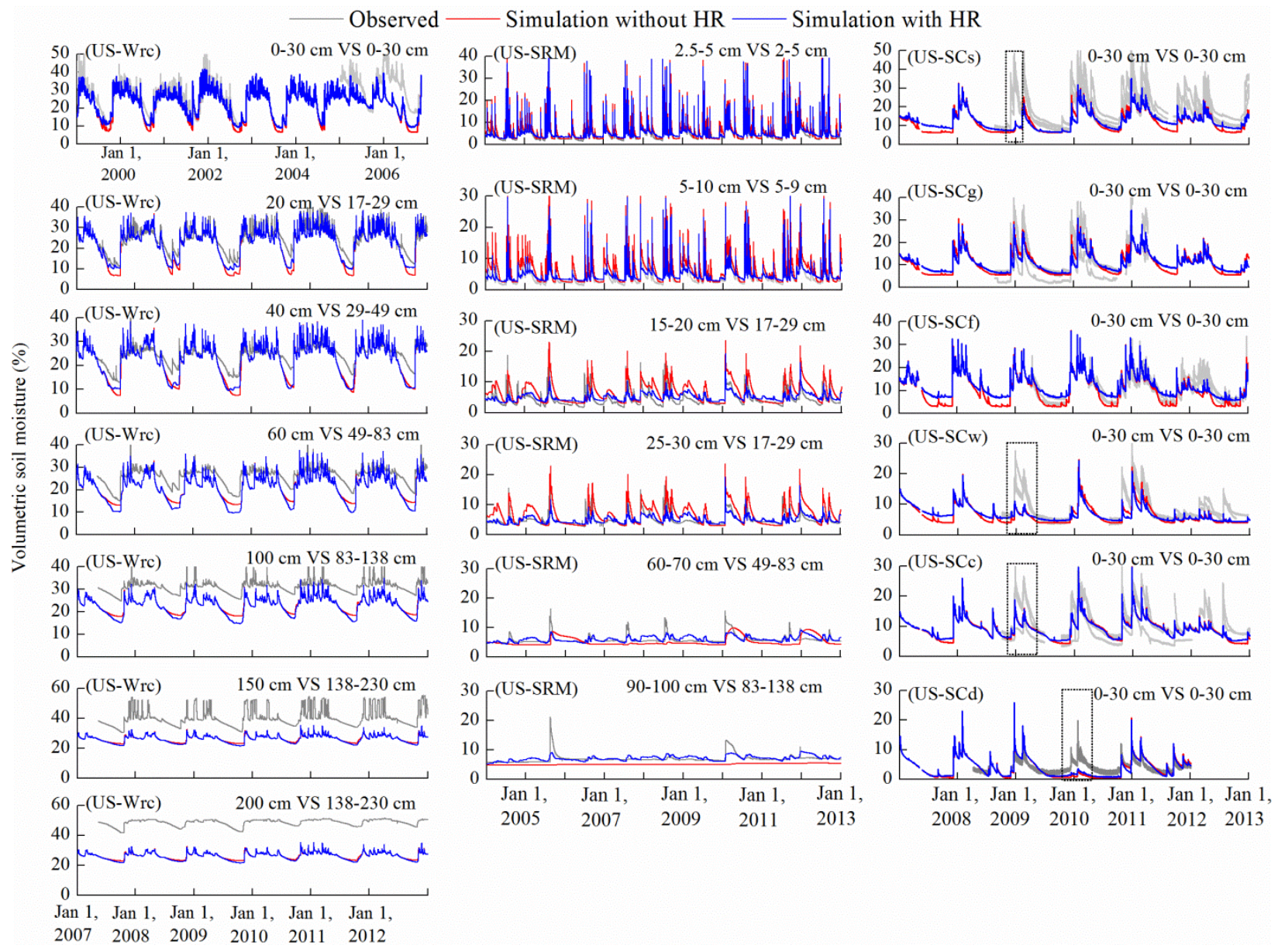

Figure. Observed and simulated soil moisture over multiple years. Labels at the upper right corner of each soil moisture panel show the depths of observed and simulated soil moisture. For example, " $20 \mathrm{~cm}$ VS 17-29 cm" means the observation depth of soil moisture is $20 \mathrm{~cm}$ and the simulated results at depths of 17-29 cm were compared with this observation. Within panels for southern California sites (US-SCs, US-SCg, US-SCf, US-SCw, US-SCc, and US-SCd), the four grey lines are data from the four CS-616 soil moisture sensors at $0-30 \mathrm{~cm}$ depth.

Several noticeable discrepancies between modeled and measured rainy season soil moisture at the Southern California US-SC sites are indicated with grey rectangular boxes in above figure. At the USCs Sage site (top-most panel), during Nov. 25 - Dec 31 2008, only $20.6 \mathrm{~mm}$ of rain were recorded, leading to only a very small modeled soil moisture increase. However, both the CS-616 (Fig.1) and CS229 (Fig. S2) soil moisture probes show a strong excursion in soil moisture during that period, congruent with large excursions at the nearby US-SCg grassland site where far more precipitation 
$(130.5 \mathrm{~mm})$ was measured during the same time frame. Several explanations are possible; precipitation data may have been lost (and mistakenly coded to zero) at the sage site during that period, but that seems unlikely, since some rainfall was recorded in spurts throughout the time frame. Alternatively, rainfall may have been very patchy on the landscape during that period, US-SCg was hit with rain more heavily than US-SCs, but water moved into soil at US-SCs from nearby areas where heavy rain fell. Similar discrepancies are visible between modeled and measured soil moisture during the same wet season at the US-SCw Pinyon and US-SCc Chaparral sites (marked with rectangles), at the same two sites during the early 2012 wet season, and at the US-SCd Sonoran Desert site during early 2010; interestingly, both the 2008/2009 and 2011/2012 wet seasons were the driest of the five years shown in the figures. The tipping bucket rain gauge used at the sites has $0.2 \mathrm{~mm}$ resolution, and accuracy of $+/-$ $1 \%$ at $50 \mathrm{~mm} \mathrm{~h}^{-1}$. 